\title{
Automatic Water Monitoring System For Tilapia Culture With Mobile Application
}

\author{
Engr. Jose Marie B. Dipay \\ ${ }^{a}$ Faculty Researcher, Institute of Technology, Research Management Office, Polytechnic University of the Philippines
}

Article History: Received: 10 November 2020; Revised 12 January 2021 Accepted: 27 January 2021; Published online: 5 April 2021

\begin{abstract}
This disquisition output will profit many people specially those who are adapting Tilapia Culturing.The pattern and sketch in this project evincive the implementation of an automatic water monitoring system for the tilapia culture. This system is automatically obtained and monitor important water parameters namely: Temperature and Potential Hydrogen (pH) level. I as a researcher, I discover also the problems when it comes into maintaining the water parameter needed by the fish without even frequently looking at the following: poor water maintenance system, contamination all over the water and number of tilapia dying by high or low ph level in water. The suitable attribute of the water monitoring system that must be improved to discourse the problems that I found out were: ph meter can make the process of water monitoring more enhance, faster, easier and the whole research output was be successfully improved water monitoring system that will help the research output to maintain the temperature of the water. When it comes to the ratings of the respondents for the Automatic Water Monitoring System for Tilapia Culture with Mobile Application were extremely receivable when it comes in the field of proficiency, performance, ability to give a good service and efficacy of this research output. To evade having a trouble or dilemma in monitoring water for tilapia culture, the government and the other authorities who have a power, they accommodate the correct usage of the propose system. One of the best way to avoid causing problem is to have a seminar that held by BFAR personnel, this seminar is all about how our technology helps to make proper reproduction of tilapia and with this action, they will get an idea to enhance and brought up a better system that the proponent produced.
\end{abstract}

Keywords: parameter, tilapia, hydrogen, microcontroller, temperature

\section{Introduction}

At the point when time passes by aquaculture creation likewise nonstop to extend and develop all alone. Philippines is a nation that is encompassed by various waterway and angling become one of the essential sustenance. Aquaculture is comprises of mollusks, fish, shellfish, sea-going plants in crisp water, ocean water air and harsh water since it is the cultivating of amphibian life forms.

Philippines isn't freed on creating Tilapia, it is a freshwater fish that has a place with the genealogy of Cichlid. Tilapia and cichlid share numerous things for all intents and purpose yet there are additionally significant contrasts. At the point when we state cichlid it occupy a large number of the tropical and semitropical zones on the planet while tilapia are one of the essential club of nourishment angles far and wide, particularly in the tropical and semi-tropical zones and it have been refined for a large number of years.

In 2004, with the full-scale creation of 3.93 million metric huge amounts of fish, mollusk, sea-going plants and shellfish, the Philippines become positioned ninth amidst top fish delivering nations on the planet. It additionally contributes $4.3 \%$ at constant costs of the Gross Domestic Product (GDP).

The nature of the water is the aggregate of biologic, compound and physical parameters; it influences intensification and purpose of living beings that is refined. Aquacultures tries have triumphed that is depend on giving a most ideal climate to have a quick development on minimal use of assets. The nature of water likewise affected general stipulation of creature that is refined when it discover energy and enhancement stipulation of life forms that is refined. I thusly presume that water's quality is fundamental component to keep and thought about when we are looking at making an arrangement to accomplish aquaculture's grandiose assembling. Despite the fact that aquaculture fish's milieu is recondite procedure and it is comprising of different nature of water factors yet less of them play believable capacity. Temperature, suspended solids and don't have weakening of melted oxygen, smelling salts, nitrite, carbon dioxide and antacid are the essential parameters.

Some wise, apparent to reality that fish vigorous digestion require condensed oxygen, essential and risky parameter is melted oxygen and it requires endless controlling the creation of aquaculture framework. There's single direction to guarantee the security of fishes and that is we have to have an appropriate support of the water parameters. Extreme worry to fish may occur if the water parameters are not inside ordinary range. This pressure can prompt sickness and here and there causes the passing of fishes. Broken down oxygen is in fact basic to the 
intensification of the fishes, along these lines a kept up level of oxygen in the fish tanks will assist the fishes with cultivating while its nonattendance can stop the nitrogen cycle that expands the smelling salts substance of the water. Smelling salts is exceptionally dangerous to angle and any oceanic life forms. Smelling salts can cause fish gill harm and passing of the fishes. Water acridity and alkalinity causes pressure that influences the size of the fishes and make the invulnerable arrangement of the fish bring down that creation them powerless to sicknesses. Smelling salts likewise influences the multiplication limit of the fishes making the creation of the fishes low. A high or low temperature additionally has a gigantic impact to fishes' wellbeing. The fishes' breathing is influenced which may cause their intensification.

\section{Objectives Of The Study}

The main problem that the design seeks an answer is how to monitor and maintain specific water parameters such as ammonia content, $\mathrm{pH}$ level and temperature to retain the health of the fishes and to stabilize the growth of our fishes. Specifically, the study seeks to answer the following;

1. What are the dilemmas that is converged on maintaining water parameter needed of fish without even frequently looking at it?

2. What are the propagandist's rejoinder for the right attribute to be improved to perorate the dilemmas runs into?

3. What are therespondents' level of espousal toward the enhanced water monitoring system in terms of:

\subsection{Performance;}

3.2. Portability;

3.3. Operability; and

3.4. Efficacy?

\section{Theoretical Framework}

It was proposed in 1936 by the biologist, Ludwig von Bertalanffy, and further enhanced by Ross Ashby, it is the Input-Process-Output (IPO) Model of evaluation based on the General Systems Theory that the researcher utilized.

When we talk about IPO or Input-Process-Output, it is required processing tasks required to transform inputs into outputs and it is also a functional graph that identifies the inputs, outputs. The IPO Model offers an efficient way to both analyze and document the perilous aspects of a transformation process if it is used in a correct or proper way. The inputs deputize the flow of data and materials into the process from the outside. The outputs are the data and materials flowing out of the transformation process. The model are sometimes configured to include any storage that might happen in the process as well. The processing step includes all tasks required to effect a transformation of the inputs

The Output shown the outcomes of the disquisition and then the process featured the procedures underwent by the researcher in order to answer the sub-dilemmas and the last part is that the Input included the formulation of the system, the hardware, the software, and the implementation of the system.

\section{Materials And Methods}

The proponents consider research as one way of discovering, interpreting and developing methods and systems for the advancement of human and giving solutions to problems. In order to achieve the main goal for a research, different method should be utilized. Such methodology will serve as an outlook on research. They set out an image for what the research is and how it should be carried out. In this study, the proponents use constructive and exploratory method of research. Constructive research helps to develop solutions to a problem. This type of approach demands a form of validation that doesn't need to be quite as empirical. This may involve evaluating the construct or new model, software or framework being developed analytically against some predefined criteria or performing some standard tests with the prototype. Another type of research method is the exploratory research, where it provides the proponents an insight and makes comprehension of an issue or situation. It should draw definitive conclusions only with extreme caution. Exploratory research helps determine the best research design, data collection method and selection of subjects. As what the exploratory research is, the proponents often relies on secondary research such as reviewing available literature and/or data, or qualitative approaches such as informal discussions with experts, beneficiaries, stakeholders, and more formal approaches through in-depth interviews, projective methods, case studies or pilot studies. The proponents tapped all resources that would be viable to the realization of the study. All efforts are exerted and rigorous analysis and brainstorming in bringing this study to accomplished and successful.The instruments that have been utilized in this study are observations 
ocular inspection, interviews, books, journals, internet, and reports records. Observations help us to identify what the design project will create. An interview is one way to consult the beneficiaries' requirements and the significance of the design project to them. Reviewing literature and related studies that similar to the project concept from books, journals, internet, and report records are other research instrument to use. The proponents believe that these research instruments will help, analyze and scrutinize how the design project will make efficient, functional, and useful to our beneficiaries and all stakeholders that are affected to the project. Since the study involves water parameter for breeding fishes the proponents interviewed personnel from Bureau of Fish and Aquatic Resources. They provide us the information and statistics needed for the study. Furthermore, they referred us to the National Inland Freshwater Technology Center, the substation that designated as national center for carp production, research and culture of freshwater fishes.

\section{Outcomes And Explanation}

1. Dilemma that is converged on maintaining water parameter needed of fish without even frequently looking at it.

The propagandist allocate three (3) topics on maintaining water parameter needed of fish without even frequently looking at it namely: 1) poor water maintenance system; 2) contamination all over the water; and 3) number of tilapia dying by high or low ph level in water during symposium.

\section{Propagandist's rejoinder for the right attribute to be improved to perorate the dilemmas runs into}

The right attributes of water monitoring system that should be enhanced to perorate the dilemmas run into, were: 1) ph meter can create the system and arrangement of water monitoring quick and more convenient; and 2) the entire set was swimmingly improved water monitoring system that will retain the coldness and hotness of the water.

3. Respondents' level of espousal toward the enhanced water monitoring system 3.1. Performance

Table 1. Propagandist's Degree of Espousal with the terms of Performance of

Automatic Water Monitoring System for Tilapia Culture with Mobile Application

\begin{tabular}{|l|l|l|l|}
\hline Declaration & $\begin{array}{l}\text { Mean } \\
\text { Rejoinder }\end{array}$ & Elucidation & Position \\
\hline $\begin{array}{l}\text { System present } \\
\text { efficacious water } \\
\text { monitoring }\end{array}$ & 4.81 & $\begin{array}{l}\text { Extremely } \\
\text { Receivable }\end{array}$ & 1.5 \\
\hline $\begin{array}{l}\text { System monitors } \\
\text { water ph level } \\
\text { accurately }\end{array}$ & 4.78 & $\begin{array}{l}\text { Extremely } \\
\text { Receivable }\end{array}$ & 2.5 \\
\hline $\begin{array}{l}\text { Arrangement of } \\
\text { the working } \\
\text { process is more } \\
\text { convenient to } \\
\text { comprehend }\end{array}$ & 4.71 & $\begin{array}{l}\text { Extremely } \\
\text { Receivable }\end{array}$ & 4.5 \\
\hline $\begin{array}{l}\text { Correct } \\
\text { monitoring of } \\
\text { water } \\
\text { temperature }\end{array}$ & 4.58 & Receivable & 5 \\
\hline $\begin{array}{l}\text { Declaration } \\
\text { Rystem present } \\
\text { efficacious } \\
\text { water } \\
\text { monitoring }\end{array}$ & $\mathbf{4 . 8 1}$ & $\begin{array}{l}\text { Extremely } \\
\text { Receivable }\end{array}$ & $\mathbf{1 . 5}$ \\
\hline
\end{tabular}


Table 1 presents propagandist's degree of espousal with the terms of performance of Automatic Water Monitoring System for Tilapia Culture with Mobile Application. System shows efficacious water monitoring mean of 4.81 (extremely receivable); system monitors water ph level accurately, 4.78 (extremely receivable); the arrangement of operation is easy to understand, 4.71 (extremely receivable); correct monitoring of water temperature, 4.58 (receivable) and eases the work of fish pond owners or BFAR personnel, 4.72 (extremely receivable).

In the field of technology that is full of information, performances are very essential in summarizing possibility and assumptions about water monitoring system and what it can do for a user. Personality of product was use by shopkeeper to recognize its attributes and let the user to gain unit of aptitude (2017,Rouse). Automatic Water Monitoring System for Tilapia Culture with Mobile Application is extremely receivable by the propagandists with the terms of performance. This is attained from total value assessment of 4.72. This arrangement may get better degree of negotiability. With its use with th mobile application, it is the one who make our research possible because the monitoring can only see with the use of mobile application. It is the one who will lead us to know what the dilemma is in the system and it is also make our system more easy and stable.

\subsection{Portability}

Table 2. Propagandists' Degree of Espousal with the Terms of the Portability of Automatic Water Monitoring System for Tilapia Culture with Mobile Application

\begin{tabular}{|l|l|l|l|}
\hline Declaration & $\begin{array}{l}\text { Mean } \\
\text { rejoinder }\end{array}$ & Exposition & Rank \\
\hline $\begin{array}{l}\text { The water } \\
\text { monitoring } \\
\text { system provide } \\
\text { advisable } \\
\text { output under } \\
\text { of the set of } \\
\text { role }\end{array}$ & 5.71 & $\begin{array}{l}\text { Extremely } \\
\text { Receivable }\end{array}$ & 2.5 \\
\hline $\begin{array}{l}\text { System can be } \\
\text { helpful for } \\
\text { decision } \\
\text { making } \\
\text { process. }\end{array}$ & 5.67 & $\begin{array}{l}\text { Extremely } \\
\text { Receivable }\end{array}$ & 4 \\
\hline Overall Mean & $\mathbf{5 . 6 2}$ & $\begin{array}{l}\text { Extremely } \\
\text { Receivable }\end{array}$ & \\
\hline
\end{tabular}

Table 2 shows the rpropagandists's degree of espousal with the terms of portability of Automatic Water Monitoring System for Tilapia Culture with Mobile Application. It indicates that the accurate water ph level monitoring outcome together with partial value 5.66 (receivable); accurate water temperature monitoring, 5.43 (receivable); the water monitoring system provides good output based on the given function, 5.71 (extremely receivable); and system can be help for decision making process, 5.67 (extremely receivable).

I as a researcher, portability of a process became specified, researchers are frequently faced with the job of recognizing the piece that make so much dilemmas in the process of system so that it is able to prioritize improvements in pattern and resources especially the endeavor of process enhancement to the sites that will have the biggest collision on the process efficacy. Portability is an example factors taken into remuneration to know the best way to get process objectives to fit with the user's pieces. The process is extremely receivable to the propagandists' with the terms of portability. This result was attained from total value assessment of 5.69. 


\subsection{Operability}

Table3. Respondents' Level of espousal in Terms of the Usability of Automatic Water Monitoring System for Tilapia Culture with Mobile Application

\begin{tabular}{|l|l|l|l|}
\hline Declaration & $\begin{array}{l}\text { Mean } \\
\text { Rejoinder }\end{array}$ & Elucidation & Position \\
\hline $\begin{array}{l}\text { The system is } \\
\text { accessible in } \\
\text { every users }\end{array}$ & 4.81 & $\begin{array}{l}\text { Extremely } \\
\text { Receivable }\end{array}$ & 2 \\
\hline $\begin{array}{l}\text { Water monitoring } \\
\text { system makes } \\
\text { tilapia to stay } \\
\text { alive and healthy }\end{array}$ & 4.89 & $\begin{array}{l}\text { Extremely } \\
\text { Receivable }\end{array}$ & 1 \\
\hline $\begin{array}{l}\text { Monitoring of } \\
\text { water and } \\
\text { temperature and } \\
\text { ph level are } \\
\text { consistent }\end{array}$ & 4.64 & $\begin{array}{l}\text { Extremely } \\
\text { Receivable }\end{array}$ & 4 \\
\hline $\begin{array}{l}\text { System is easy to } \\
\text { manipulate }\end{array}$ & 4.78 & $\begin{array}{l}\text { Extremely } \\
\text { Receivable }\end{array}$ & 5 \\
\hline Total Value & $\mathbf{4 . 7 8}$ & $\begin{array}{l}\text { Extremely } \\
\text { Receivable }\end{array}$ & \\
\hline
\end{tabular}

Table3 provide the propagandists' degree of espousal with the terms of operability of Automatic Water Monitoring System for Tilapia Culture with Mobile Application. It infers that the system is accessible with the partial value assessment, 4.81(extremely receivable); water monitoring system makes tilapia to stay alive and healthy, 4.89 (extremely receivable); monitoring of water temperature and ph level are consistent, 4.64 (extremely receivable); and system is easy to manipulate, 4.78 (extremely receivable).

I therefore conclude that once aforesaid that operability is the basis of the uniqueness of a user's knowledge when concur to produce the same effect with process and experience. Based on the statement of Britsios, he said that users will become comp laced, calm with process; it will refine relegation and confidence with the process. Britsios (2017)

Process that is provided by system is extremely receivable to the propagandists' with the terms of the operability. This is attained from the total value assessment of 4.78 .

\subsection{Efficacy}

Table 4. Propagandists' Degree of Espousal Concerning the Efficacy of Automatic Water Monitoring System for Tilapia Culture with Mobile Application

\begin{tabular}{|c|c|c|c|}
\hline Declaration & $\begin{array}{l}\text { Mean } \\
\text { Rejoinder }\end{array}$ & Elucidation & Declaration \\
\hline $\begin{array}{l}\text { There is receivable } \\
\text { rejoinder } r \text { and } \\
\text { making a method } \\
\text { time }\end{array}$ & 4.60 & $\begin{array}{l}\text { Extremely } \\
\text { Receivable }\end{array}$ & $\begin{array}{l}\text { There } \\
\text { receivable } \\
\text { rejoinder and } \\
\text { making a } \\
\text { method time }\end{array}$ \\
\hline $\begin{array}{l}\text { Evidence restoration } \\
\text { ought to quick and } \\
\text { more convenient }\end{array}$ & 4.74 & $\begin{array}{l}\text { Extremely } \\
\text { Receivable }\end{array}$ & $\begin{array}{l}\text { Evidence } \\
\text { restoration ought } \\
\text { to quick and } \\
\text { more convenient }\end{array}$ \\
\hline $\begin{array}{l}\text { Proficient } \quad \text { of } \\
\text { fulfilling varied } \\
\text { activity in a definite } \\
\text { season }\end{array}$ & 4.74 & $\begin{array}{l}\text { Extremely } \\
\text { Receivable }\end{array}$ & $\begin{array}{l}\text { Proficient of } \\
\text { fulfilling varied } \\
\text { activity in a } \\
\text { definite season }\end{array}$ \\
\hline Total Value & 4.69 & $\begin{array}{l}\text { Extremely } \\
\text { Receivable }\end{array}$ & Total Value \\
\hline
\end{tabular}


Table 4 provides the propagandists' degree of receivable concerning the efficacy of Automatic Water Monitoring System for Tilapia Culture with Mobile Application. It insinuates that there's receivable rejoinder and making method time with the total value of 4.60 (extremely receivable); data restoration should be quick and more convenient, 4.74 (extremely receivable); and proficient of fulfilling varied activity in a definite season, 4.74 (extremely receivable).

Efficacy insures that the functions, ability, tasks, experiences, tools are applied at every angle or portion of the utilization. It pledges the enterprise will be created and well designed, executed and operationally assisted to sight hank requirements (Cover \& Tomas, 2016).

The process is extremely accepted by the propagandists with the terms of efficacy. This is attained from the total value assessment of 4.69 .

\section{Conclusions And Recommendations}

\section{Conclusion}

The dilemmas encountered in retaining the water parameter needed by the fish without even frequently looking at were: poor water maintenance system, contamination all over the water and number of tilapia dying by high or low ph level in water.The right attributes of water monitoring system that should be enhanced to perorate the dilemmas run into were: ph meter can create the system and arrangement of water monitoring quick and more convenient and the entire set was swimmingly improved water monitoring system that will retain the coldness and hotness temperature of the water sample target users.

\section{Recommendation}

LGUs to begin utilizing the system and educate their constituents on suitable use and better water monitoring system fish farmers and fish pond owners.

\section{References}

"Britsios, J. (2017). Webnauts.net. Retrieved from Why usability is important to you: http://www.webnauts.net/usability.html"

"Crossman, A. (2017, March 02). thought co. Retrieved from Understanding Purposive

Sampling: An Overview of the Method and Its Applications: https://www.

Thoughtco.com/purposive-sampling-3026727

Rouse,M.(2017). searchmicroservices.techtarget. Retrieved from functionality:"

"http://searchmicroservices.techtarget.com/definition/functionality"

"Sevilla, C. G. (1992). Research Methods: Revised Edition. Quezon City: Rex."

"Thomas M. Cover, Joy A. Thomas (2006). Elements of Information Theory. John Wiley\& Sons, New York."

"Ihab Adly, Hossam E. M. Sayour, Nahla M. Badawy and Hani Ragai"(2013, September):EVALUATION OF REAL-TIME WATER QUALITY MONITORING

SYSTEM IN NILE TILAPIA- LETTUCE AQUAPONIC BASED ON

WIRELESS SENSOR NETWORK

"Weibull. (2013, March). Retrieved from Reliability Importance: http://www.weibull. com/hotwire/issue145/tooltips145.htm"

“Zikmund, W. G. (2003). Business Research Methods. Ohio: Thomson South-Western". 